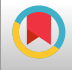

\title{
Functions, Structure and Activities of the Institutional Research Unit of Iranian Medical Sciences Universities
}

\author{
Abbas Abbaspour ${ }^{1}$, Vida Sepahi (iD) ${ }^{2}$, Parviz Saketi ${ }^{3}$, Farid Najafi (iD ${ }^{4}$, Ahmad Khoshay (iD ${ }^{5}$ and Mansour \\ Rezaei (iD) ${ }^{6, *}$ \\ ${ }^{1}$ Department of Educational Management and Planning, Faculty of Psychology and Educational Sciences, Allameh Tabatabaei University, Tehran, Iran \\ ${ }^{2}$ Education Development Center, Kermanshah University of Medical Sciences, Kermanshah, Iran \\ ${ }^{3}$ Department of Educational Management and Planning, Faculty of Psychology and Educational Sciences, Shiraz University, Shiraz, Iran \\ ${ }^{4}$ Department of Epidemiology, Research Center for Environmental Determinants of Health, Faculty of Public Health, Kermanshah University of Medical Sciences, \\ Kermanshah, Iran \\ ${ }^{5}$ Department of Nursing, Faculty of Nursing and Midwifery, Kermanshah University of Medical Sciences, Kermanshah, Iran \\ ${ }^{6}$ Department of Biostatistics, Social Development and Health Promotion Research Center, Kermanshah University of Medical Sciences, Kermanshah, Iran \\ "Corresponding author: Professor of Biostatistics, Department of Biostatistics, School of Health, Kermanshah University of Medical Sciences, Kermanshah, Iran. Email: \\ rezaei39@yahoo.com
}

Received 2019 April 10; Revised 2019 July 13; Accepted 2019 August 13.

\begin{abstract}
Background: The fast pace and complicated nature of the environmental changes taking place and the problems ahead make academic decision-making a challenge for managers that cannot be overcome unless with the application of scientific studies. Institutional Research (IR) units deserve more attention now than before as effective decision-making tools using scientific findings.

Objectives: The present study was conducted to determine the functions and structure of medical sciences universities and the activities of IR units.

Methods: This qualitative study was carried out through a directed content analysis. The IR unit pertained to Kermanshah University of Medical Sciences (KUMS). The documents of the official duties of KUMS were analyzed and compared in this research. Directed content analysis was used to enable proper comparisons and data analysis. In the first part of the study, the theoretical foundations were examined and a review of literature was performed on IR units, and by adapting Volkwein's model, a conceptual model consisting of IR components was drawn. In the second part, the documents of the official duties of KUMS were encoded and categorized and the categories extracted were then divided into 17 domains of IR activities based on the conceptual model, which were then compared and analyzed.

Results: The results showed that, out of the 17 activities extracted from the theoretical foundations and the review of literature by the researcher, nine activities are already implemented in four major functions of IR units, and the largest IR unit was the Education Development Center (EDC) for medical sciences. This study also explains the structure and status of IR units in Iranian medical sciences universities.

Conclusions: Medical sciences universities can complete the tasks of the EDC or establish a new structure as a separate unit at the university for IR implementation functions. The results can work as a guide for reflecting on and taking action about the establishment of an IR office at medical sciences universities throughout Iran.
\end{abstract}

Keywords: Institutional Research, Medical Sciences, Higher Education

\section{Background}

The increase in the number of students and applicants, the development and diversification of educational organizations, the internationalization of higher education, the rapid and complex environmental changes, the changes in the expectations of stakeholders and the problems ahead, such as the reduction of financial resources, information explosions and the speed of new technologies have put universities in complex situations regarding decision-making and management. Academic decisionmaking has become a challenge for managers that mandate the use of scientific studies (1). The complexity of the health system and the necessity of evidence-based policies necessitate the establishment of a health policy system based on acceptable criteria and features (2). To take advantage of effective decision-making tools and scientific research in academic decisions and to prevent preferencebased and emotional decision-making, the process of Institutional Research (IR) unit should be emphasized more 
than ever before (3). IR refers to any research activity performed in higher education settings to provide data to decision-makers and policy-makers. IR offices are responsible for managing data and reporting them across universities, and as the focal point for decision-making, these offices constitute major institutions that can report and provide information on the performance and prospects of universities at the management level to collect, analyze and publish policies and decisions (4). The key role and significance of this unit mandate its establishment in order to solve the existing crises in higher education and decisionmaking in universities (5).

At present, this unit is considered one of the pillars of leading universities that serves different purposes, such as providing consulting for policy-making, planning and decision-making processes based on research, and preparing analytical reports on the status of students, faculty members, university staff, etc. (6). If university is considered the center of thought and reason in the society, IR should then be considered the center of decision-making and organizational intelligence in universities. The role of IR in the decision-making process at the university includes the transformation of data and information into managerial wisdom and executive queues (7).

Calderon and Mattis (2013) noted that the role of higher education institutions has permanently changed in the highly competitive global environment and emphasized the importance of establishing centralized units such as IR offices. They also recommended that IR experts build the necessary skills (both general and specialized) for management and policy-making so as to help realize the visions of higher education institutions. These experts need to possess the ability to innovate and survive in complex and uncertain work environments (8). Delaney(2009) examined the ways of increasing the value of IR scholars by developing their role in policymaking, planning, evaluation and assessment and the adoption of new roles in program design and knowledge production. IR scholars can be of great use to higher education in the 21st century through the expansion of their current roles and the acceptance of new roles to affect the decision-making process (9). Volkwein proposed 18 components for IR, including: (1) comparative study and modeling, (2) strategic planning, (3) evaluation of student performance, (4) validation, (5) academic effectiveness, (6) evaluation of educational and management programs, (7) educational analysis, (8) improving faculty members, (9) examining campus atmosphere and student life, (10) evaluation of comprehensive quality management and continuous improvement of quality, (11) improvement of curriculum, (12) registration and maintenance management, (13) knowledge and technology management, (14) resource management,
(15) analysis of students' registration, (16) financing, (17) the relationship of students associations, and (18) performance evaluation and accountability. Volkwein's endeavor comprises the framework of the present study $(3,10)$.

Of all the components of IR discussed by scholars, 17 are categorized into four aspects according to Volkwein's theory and based on the internal experiences of studying in this research as the components of the selected university (Figure 1). These components form a conceptual pattern and the base for achieving the research objectives.

The purpose of medical education is to train expert personnel capable of providing quality services in the health care system, and the level of medical education is assessed by the needs of the society. Quality improvement can be accomplished by both internal improvement and external accountability. IR units in medical sciences universities can play a major role in the health system's accomplishments and contribute to the achievement of the 12 policies of the health system by problem-solving, information communication and guideline development for the design and implementation of health policies and programs. In addition to managing and transferring knowledge, they also serve other purposes, as discussed by Volkwein $(3,10)$. Despite the long history of IR in advanced countries and its effect on policymaking, planning and decision-making, to date, it has not been integrated in any Iranian medical sciences universities for applied sciences. Decisionmaking and policy-making in medical sciences universities is based on the desires and views of the members of their official councils.

\section{Objectives}

Establishing such unit in universities across the country, especially medical sciences universities, requires further attention to infrastructures. The present study seeks to demonstrate the efforts in IR at Kermanshah University of Medical Sciences (KUMS) and the organizational units or players who are currently involved in IR in this institution. We also seek to know how the existing structures relate to IR organized in KUMS.

\section{Methods}

This qualitative study was conducted using the directed content analysis. The documentary method and collaborative observation were used for data collection. In the first part of the study, the theoretical foundations of the research were studied and a review of literature on IR was performed and Volkwein's model (1999 and 2008) was adapted to draw a conceptual model consisting of the components of IR. In the second part, documents of the official 


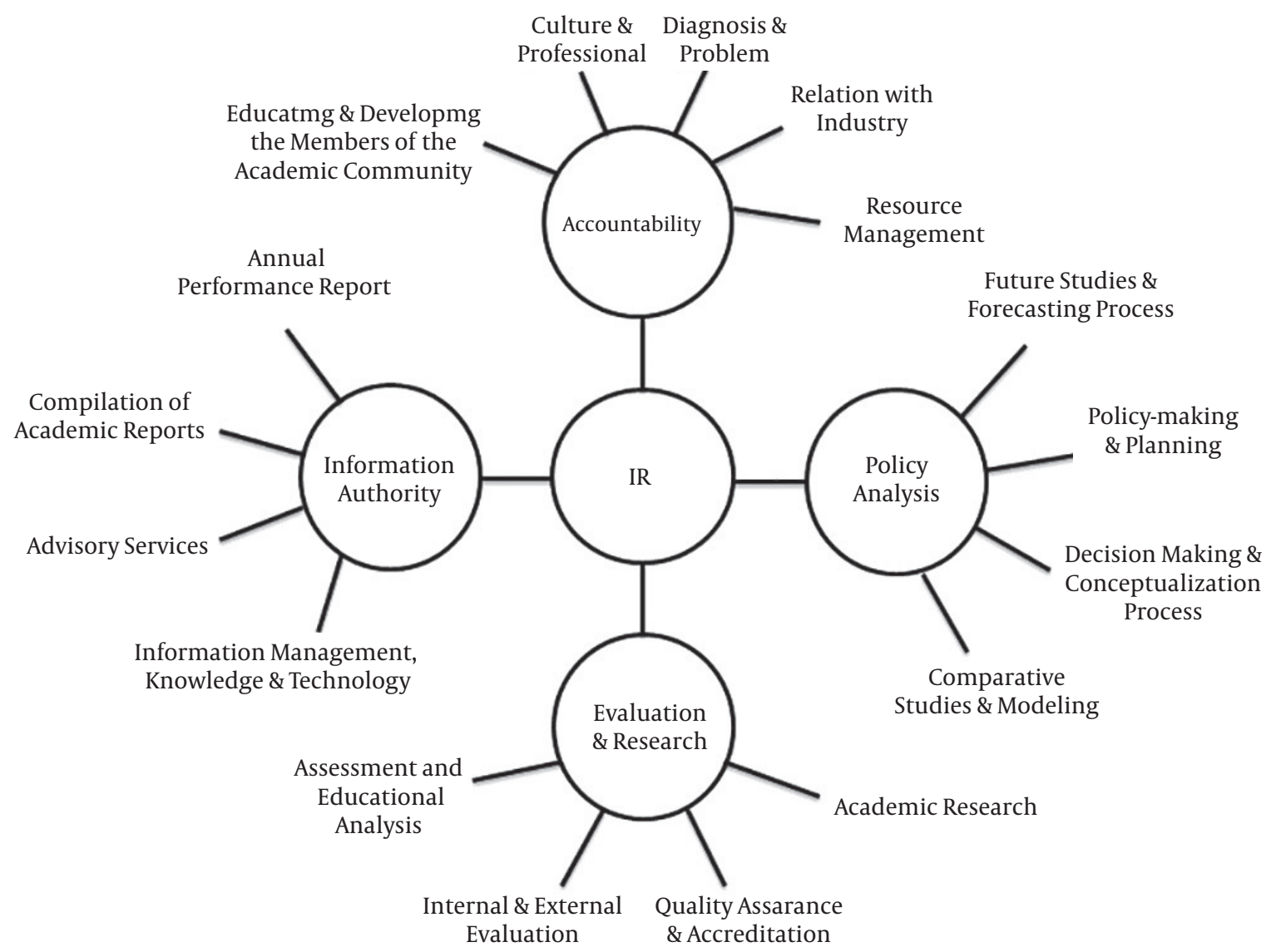

Figure 1. The conceptual model of IR and its components

duties ( $n=19)$ of the KUMS, prepared in accordance with the regulations of the Ministry of Health and Medical Education (MHME), were first reviewed. These documents were then open-encoded and categorized using the deductive method. The categories extracted from the official duties of KUMS were next compared with the 17 components of the activities of IR derived from the conceptual model. This comparison led to the emergence of the same themes as the IR components identified in the official duties of KUMS.

\section{Results}

Adapting Volkwein's model (1999) leads to four main functions for IR, including the concepts of (1) accountability, (2) analysis of the policies, (3) evaluation and research, and (4) information authority. These functions were defined and formed the basis of a comparative-analytical re- view of the official duties of medical sciences universities (in the case of KUMS).

Using open-source coding, the text of the official documents of KUMS was summarized (Appendix 1 in Supplementary File). In order to study shared activities using the model extracted from the theoretical foundations and the literature review of IR, as summarized by the researcher, it can be concluded that the components of the 17 dimensions of IR units in the official documents are similar to the 17 aspects of IR activities. More precisely, these similar themes are the actions taken in medical universities of Iran with regard to IR so far (Table 1).

The review of literature and content analysis of the duties of university councils as well as the decision-making units of KUMS suggest that the activities of the councils and the decision-making units of KUMS are related to the functions of IR units in some cases (Table 2). In other cases, 


\begin{tabular}{|c|c|c|c|}
\hline No. & Theme/Component of IR & Subcomponent of IR & $\begin{array}{l}\text { Presence of the } \\
\text { Component }\end{array}$ \\
\hline & Accountability & & \\
\hline \multirow{2}{*}{$\mathbf{1}$} & \multirow{2}{*}{ Development of academic culture and professional ethics } & Academic culture & No \\
\hline & & Professional ethics & Yes \\
\hline \multirow{2}{*}{2} & \multirow{2}{*}{ Diagnosis and problem solving in order to improve quality } & Problem-solving & No \\
\hline & & Diagnosis & No \\
\hline \multirow{2}{*}{3} & \multirow{2}{*}{ Relations with industries and the society } & Communication within the university & Yes \\
\hline & & Community and environmental responsiveness & Yes \\
\hline \multirow{2}{*}{4} & \multirow{2}{*}{ Resource management at the university } & Funds & Yes \\
\hline & & Other resources & Yes \\
\hline \multirow{3}{*}{5} & \multirow{2}{*}{$\begin{array}{l}\text { Educating and developing members of the academic } \\
\text { community }\end{array}$} & Teaching faculty & Yes \\
\hline & & Training non-teaching staff & Yes \\
\hline & Policy of analysis & & \\
\hline \multirow{2}{*}{6} & \multirow{2}{*}{ Future studies and forecasting process } & Future studies & No \\
\hline & & Forecasting & No \\
\hline \multirow{3}{*}{7} & \multirow{3}{*}{ Policy-making and planning } & Policy-making & Yes \\
\hline & & Operational plans & Yes \\
\hline & & Strategic planning & Yes \\
\hline \multirow{2}{*}{8} & \multirow{2}{*}{ Decision-making and conceptualization process } & Decision-making & No \\
\hline & & Conceptualization & No \\
\hline \multirow{4}{*}{9} & \multirow{3}{*}{ Comparative studies and modeling } & Comparative studies & No \\
\hline & & Modeling & No \\
\hline & & Review successful experiences & No \\
\hline & Evaluation and research & & \\
\hline \multirow{2}{*}{10} & \multirow{2}{*}{ Academic research } & Academic research & Yes \\
\hline & & Student thesis & Yes \\
\hline \multirow{2}{*}{$\mathbf{1 1}$} & \multirow{2}{*}{ Quality assurance and accreditation } & Quality assurance & Yes \\
\hline & & Accreditation & Yes \\
\hline \multirow{2}{*}{12} & \multirow{2}{*}{ Internal and external evaluation } & Internal evaluation & Yes \\
\hline & & External evaluation & Yes \\
\hline \multirow{4}{*}{13} & \multirow{3}{*}{ Assessment and educational analysis } & Educational assessment & Yes \\
\hline & & Curriculum assessment & Yes \\
\hline & & Registration & Yes \\
\hline & Information authority & & \\
\hline 14 & Advisorv services & Consultations within the university & No \\
\hline & & Consultations outside the university & No \\
\hline & Compilation of a domic renorts & Reports within the university & No \\
\hline o & 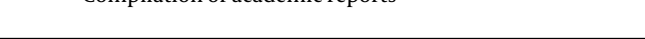 & Reports outside the university & No \\
\hline & & Management data & No \\
\hline 16 & Information management, knowledge and technology & Knowledge management & No \\
\hline & & Technology management & No \\
\hline 17 & Annual performance report & Functional data collection & Yes \\
\hline 20 & & Fact book compilation & Yes \\
\hline
\end{tabular}

there is no specific task expected.

Various measures, including the review of the goals and task description for the organizational units of KUMS, participatory observation and the organizational chart (Figure 2) approved by the MHME of the existing structure according to the functions and roles of IR from previous research objective were taken (Figure 3). In Figure 2, the staff units in the organizational structure of KUMS related to IR are marked in blue and the executive units (queues) related to IR in green, and the headquarters and the specified executive units are drawn in a new structure. 


\begin{tabular}{|c|c|c|c|c|}
\hline No. & Theme/Component of IR & Subcomponent of IR & $\begin{array}{l}\text { Presence of the } \\
\text { Component }\end{array}$ & Organizational Unit \\
\hline & Accountability & & & \\
\hline \multirow{2}{*}{1} & \multirow{2}{*}{$\begin{array}{l}\text { Development of academic culture and } \\
\text { professional ethics }\end{array}$} & Academic culture & No & - \\
\hline & & Professional ethics & Yes & $\begin{array}{l}\text { Professional Ethics Council, Department of } \\
\text { Presidency }\end{array}$ \\
\hline \multirow{2}{*}{2} & \multirow{2}{*}{$\begin{array}{l}\text { Diagnosis and problem-solving in } \\
\text { order to improve quality }\end{array}$} & Problem-solving & No & - \\
\hline & & Diagnosis & No & - \\
\hline \multirow{2}{*}{3} & \multirow{2}{*}{$\begin{array}{l}\text { Relations with industries and the } \\
\text { society }\end{array}$} & $\begin{array}{l}\text { Communication within the } \\
\text { university }\end{array}$ & Yes & $\begin{array}{l}\text { Center for Health Technology Development, } \\
\text { Vice Chancellor for Research and Technology }\end{array}$ \\
\hline & & $\begin{array}{l}\text { Community and environmental } \\
\text { responsiveness }\end{array}$ & Yes & $\begin{array}{l}\text { Center for Health Technology Development, } \\
\text { Vice Chancellor for Research and Technology }\end{array}$ \\
\hline \multirow{2}{*}{4} & \multirow{2}{*}{ Resource management } & Funds & Yes & $\begin{array}{l}\text { Vice-Chancellor in Administration and } \\
\text { Resources Development Affairs }\end{array}$ \\
\hline & & Other resources & Yes & $\begin{array}{l}\text { Vice-Chancellor in Administration and } \\
\text { Resources Development Affairs }\end{array}$ \\
\hline \multirow{2}{*}{5} & \multirow{2}{*}{$\begin{array}{l}\text { Educating and developing members of } \\
\text { the academic community }\end{array}$} & Teaching faculty & Yes & EDC Vice Chancellor for Education \\
\hline & & Training non-teaching staff & Yes & $\begin{array}{l}\text { Continuous Education, Vice Chancellor for } \\
\text { Education }\end{array}$ \\
\hline & Policy of analysis & & & \\
\hline \multirow{2}{*}{6} & \multirow{2}{*}{ Future studies and forecasting process } & Future studies & No & - \\
\hline & & Forecasting & No & - \\
\hline \multirow{3}{*}{7} & \multirow{3}{*}{ Policy-making and planning } & Policy-making & Yes & Policy Council, Department of Presidency \\
\hline & & Operational plans & Yes & Each unit separately \\
\hline & & Strategic planning & Yes & Each unit separately \\
\hline \multirow{2}{*}{8} & \multirow{2}{*}{$\begin{array}{l}\text { Decision making and } \\
\text { conceptualization process }\end{array}$} & Decision-making & No & - \\
\hline & & Conceptualization & No & - \\
\hline \multirow{3}{*}{9} & \multirow{3}{*}{ Comparative studies and modeling } & Comparative studies & No & - \\
\hline & & Modeling & No & - \\
\hline & & Review successful experiences & No & - \\
\hline & Evaluation and research & & & \\
\hline \multirow{2}{*}{10} & \multirow{2}{*}{ Academic research } & Academic research & Yes & Vice Chancellor for Research and Technology \\
\hline & & Student thesis & Yes & $\begin{array}{l}\text { Vice Chancellor for Research and Technology } \\
\text { and the Scientific Pole of Community } \\
\text { Medicine Education }\end{array}$ \\
\hline \multirow{2}{*}{11} & \multirow{2}{*}{ Quality assurance and accreditation } & Quality assurance & Yes & EDC Vice Chancellor for Education \\
\hline & & Accreditation & Yes & EDC Vice Chancellor for Education \\
\hline \multirow{2}{*}{12} & \multirow{2}{*}{ Internal and external evaluation } & Internal evaluation & Yes & EDC Vice Chancellor for Education \\
\hline & & External evaluation & Yes & EDC Vice Chancellor for Education \\
\hline \multirow{4}{*}{13} & & Educational assessment & Yes & EDC Vice Chancellor for Education \\
\hline & Assessment and educational analysis & Curriculum assessment & Yes & EDC Vice Chancellor for Education \\
\hline & & Registration & Yes & Vice Chancellor for Education \\
\hline & Information authority & & & \\
\hline 1 & Adviconuc & $\begin{array}{l}\text { Consultations within the } \\
\text { university }\end{array}$ & No & - \\
\hline 14 & Ravisory seivices & $\begin{array}{l}\text { Consultations outside the } \\
\text { university }\end{array}$ & No & - \\
\hline & & Reports within the university & No & - \\
\hline 15 & & Reports outside the university & No & - \\
\hline & & Management data & No & - \\
\hline 16 & $\begin{array}{l}\text { Information management, knowledge } \\
\text { and technology }\end{array}$ & Knowledge management & No & - \\
\hline & & Technology management & No & - \\
\hline 17 & Anpul lorformoner renort & Functional data collection & Yes & Each unit separately \\
\hline 17 & 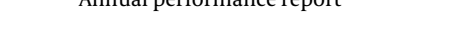 & Fact book compilation & Yes & Each unit separately \\
\hline
\end{tabular}




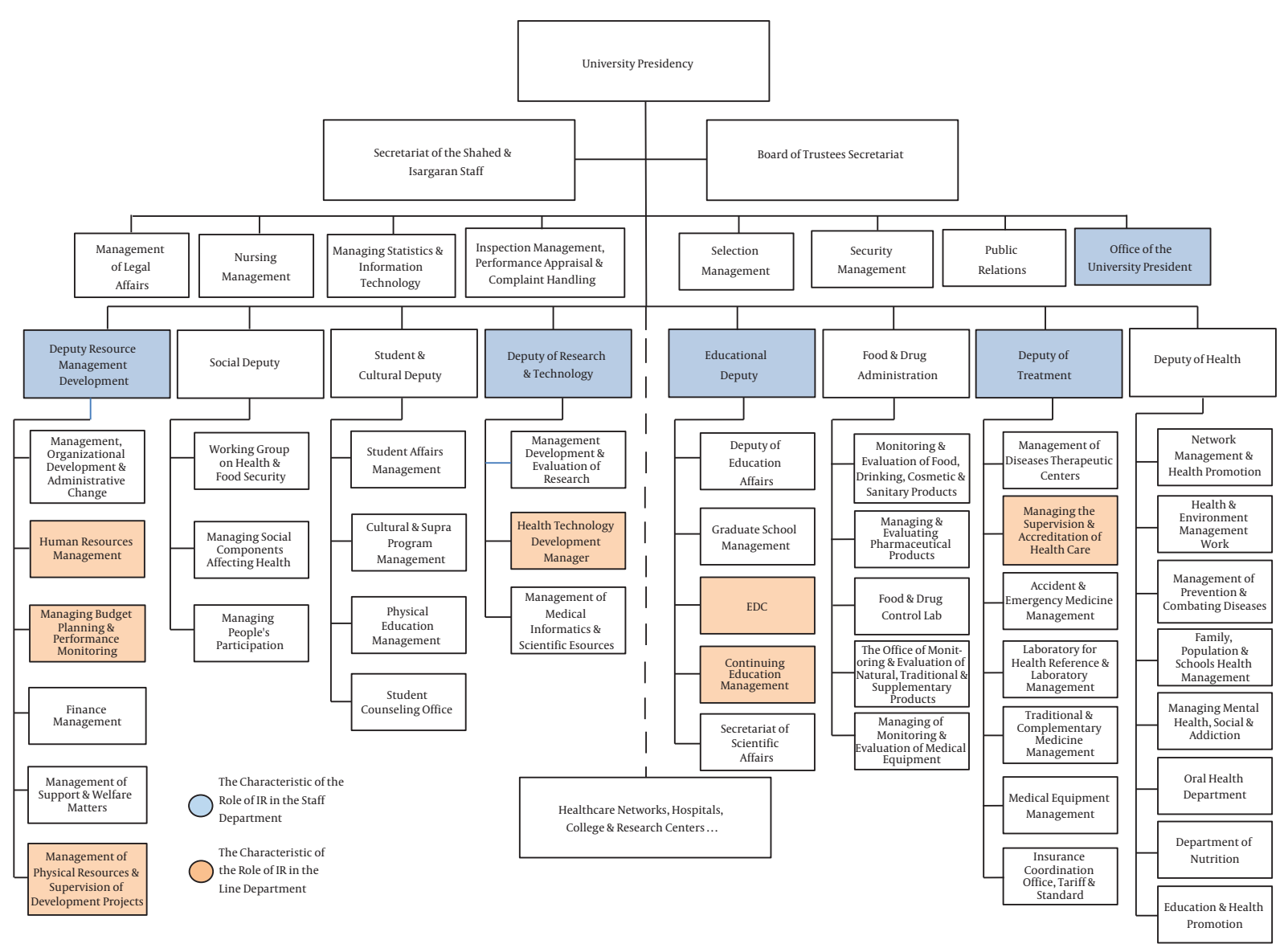

Figure 2. Organizational structure of KUMS

\section{Discussion}

The review of the documents showed that activities are performed in different parts of the university in line with the objectives of IR, but do not cover all its aspects. Overall, the results showed that, out of the 17 activities extracted from the theoretical foundations and literature review by the researchers, nine were implemented in four main Volkwein functions. The largest unit related to IR is the study of Education Development Center (EDC) for medical sciences. After the EDC, the Deputy of Research and Technology (DRT) is the unit that performs the functions of IR in academic research and development of relations with the community and industries.

The first major function of IR is accountability. IR unit experts determine the status quo of the university and plan the most appropriate situation by emphasizing the capacities and abilities of the university. Realizing this role helps secure a budget and interact with the government to provide a positive image of the university. One of the com- ponents of this function is the academic culture. The results showed that no organizational units have worked on academic culture at KUMS.

Since 2011, KUMS has had a professional ethics council that is directly supervised by the head of the university. Medical ethics comprise a fundamental issue in science and technology in Iran. On the one hand, this branch of science helps provide optimal health services and bring more satisfaction to the recipients of the services, i.e. the patients. On the other hand, it helps better respond to the demands of the community regarding the right of citizens to receive proper and equitable health care. Accordingly, medical ethics in its modern approach has exceeded the traditional issues often limited to physician and patient relationships. The laws of the country, especially the Constitution of Iran, the comprehensive scientific map of the country, the national comprehensive health plan, the general health policies as well as the general science and technology policies are all concentrated on ethics, more specifically, health ethics (11). The mission of the Com- 


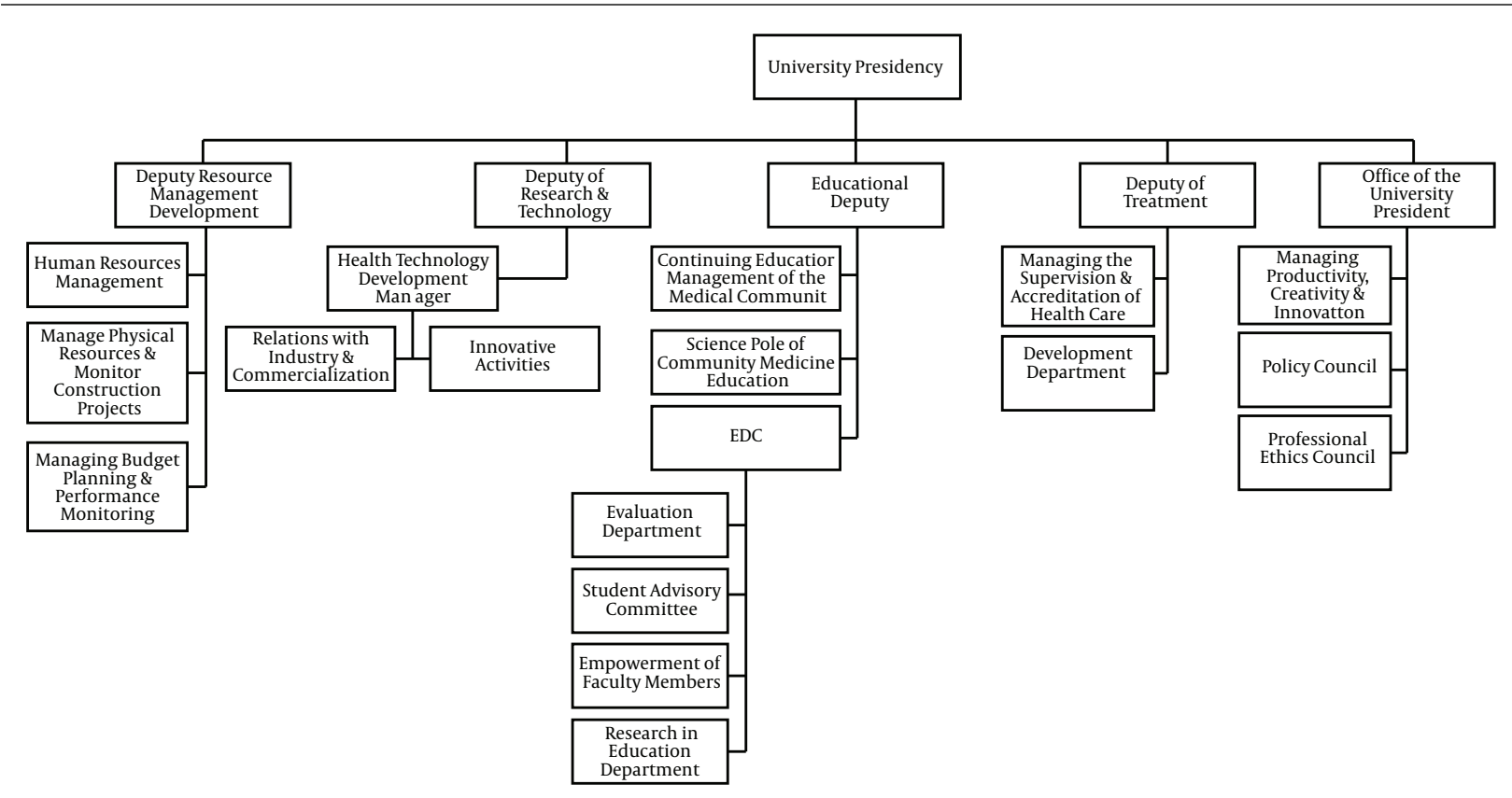

Figure 3. Organizational structure of the units conducting similar activities in IR

mittee of Strategic Planning in Medical Ethics is to gain knowledge and achieve comprehensive management (including needs-assessment, policy-making and reprogramming). Medical ethic is defined in health as the enabling of education, research and health services based on the Islamic values ruling Iran, such as respect for human dignity and justice (12).

Regarding the component of diagnosis and problemsolving in terms of quality improvement, there was no activity at the examined medical sciences university. The purpose of the complication is to diagnose the problems in the organization and provide appropriate and practical solutions to them for the purpose of quality improvement (13). The Office of Relations with Industry and Society is one of the sub-offices of the DRT of KUMS that enables cooperation with industries, organizations and executive agencies and offers advice on the provision of specialized services and executive, educational and research projects by recruiting from outside the university. Resources and co-operation in financing are of the other activities in IR, summarized in the Deputy Resource Management Development (DRMD) at the university. Another role of IR in terms of accountability is to educate and spread knowledge among members of the academic community, which is crucial in the EDC for the promotion of faculty members and in the continuing education office for staff training.

Other important functions of IR units include contributing to future studies, policy-making and planning at the university. Nowadays, the definition and realization of future research processes, futurism and politics and the subsequent strategic and operational planning at universities due to the organizational and social role of this crucial and complex institution for community development are well-recognized throughout the country. Prospective research means imprinting, pre-empting and shaping the future, and policy-making from this perspective means the adoption of large-scale decisions, for whose realization decisions have to be made in several sub-disciplines. Moreover, the ability to shift people toward the stance of influential and powerful groups at the university, such as faculty members and students, is in pursuit of policies and decisions (14). The results showed that KUMS is not very active in this regard. The final decision by the university's policy council at university level for planning and policy-making is made by consensus and it is not based on the research. In operational and strategic plans, the university operates partly and as islands, and each unit declares its plans separately.

The key word and concept in IR is research. The main function of IR is to direct academic research to enhance the quality of the university through the improvement of its internal structure and processes and its responsiveness to the external needs and changes. One of the challenges of universities is the application of academic research findings in addressing the issues and harms inside and outside the university (14). Although academic studies are con- 
ducted at the Department of Research and Technology and the results of research in education at the EDC of KUMS, the research cycle is not fully completed from policy to action so as to solve the problems of the university and society. Overall, continuous quality assurance and validation, ongoing internal and external evaluation, assessment and education analysis are considered in the evaluation role. Undoubtedly, evaluation and consequently performance management at the university are very important in achieving the desired quality, which is also important at EDC of KUMS.

Information authority is the last function of IR, and information and counseling functions contribute to the decision-making process among university managers. In this function, university scholars, as the advisors of the university president and other prestigious executives, have continuously and efficiently sought to compile, aggregate, analyze and prepare accurate, up-to-date and efficient data in line with optimal decision-making by the help of university administrators. The results of the review of the responsibilities of the organizational units of KUMS showed that, due to their limited position and mission, different departments within the university give different information to university administrators. These statistics and information presented in the form of annual reports on the university performance are not as high as the statistical reports that do not provide useful information to managers and are not 100\% reliable in academic decisionmaking.

Evaluating Tehran, Al-Zahra, Amir Kabir and Tarbiat Modares universities in Tehran and Ferdowsi University in Mashhad showed that some IR-related activities are being performed in some offices and some parts of the predicted task descriptions. The rankings of the number of activities performed in the field of IR showed that Ferdowsi University of Mashhad, with 13 activities, is first, followed by Tehran University (10 activities), Tarbiat Modares University (nine activities) and Amir Kabir University and Al-Zahra University (seven activities) (15). Moreover, examining and evaluating the organizational units of the University of Isfahan showed that 11 of the activities of the councils and decision-making units of this university were in line with the 18 activities of Volkwein. Moreover, in seven cases, i.e. the development of measures for the evaluation of performance and accountability, survey of university campus atmosphere and student life, accreditation, analysis of graduates association relationships, educational analysis, knowledge management and technology analysis, and student registration and maintenance management reports, no specific tasks were predicted and probably no studies were carried out to support policy analysis prior to decision-making at the university. The 11 items of the offi- cial duties of the University of Isfahan in the field of IR include: (1) comparative studies and modeling, (2) strategic planning report, (3) evaluation of students' performance, (4) academic effectiveness, (5) evaluation of education and management programs, (6) improving faculty members, (7) evaluation of comprehensive quality management and continuous quality improvement, (8) improving curriculum, (9) resource management, (10) analysis of the registered members, and (11) financing reports (16).

Next, the design and plan unit of Al-Zahra University, which has the most similarities to IR units, was analyzed. The director of the university organized this office. The results showed that only the duty of creating a database was similar in this unit to an IR unit; however, there were many tasks that did not correlate with the mission of an IR unit. Nonetheless, some similarities were observed in performance, activities and initiatives (17).

The Institute for Research and Planning in Higher Education is another educational institution with similar functions to IR; however, this institution has not managed to provide policies, programs, interactivity and support to universities for the establishment of IR units and to encourage them in these steps due to the existing bureaucracies (17). Currently, Iranian universities lack such units, and IR has not yet been institutionalized at universities or institutes of higher education in this country. Although, in this study, some similarities were observed between the job descriptions at KUMS and the activities of an IR unit, these activities were scattered, isolated and non-coherent. Perhaps, one can state that the only thing that matters to the University of Medical Sciences is evaluation where both educational centers and health centers are currently making progress, and many standards are currently being developed to improve the quality of the centers. The ranking of educational and therapeutic centers is based on these standards. Applied studies are being conducted and research sessions are held, but the results are not used optimally. In the leading universities of developed countries with a decentralized structure, IR units have been operating for years; examples including Harvard, Arkansas, Massachusetts, Notre Dame, Georgia and California universities (18-23).

Using the results of previous studies and considering the organizational structure currently in place at KUMS, this study extracted some of the structures related to IR. In the developed structure, out of the eight deputies under the supervision of the university's presidency, four, i.e. the deputy of treatment, DRMD, DRT and the Education Deputy (ED), were following and carrying out IR activities. Examining the organizational structure of KUMS also confirmed that the roles and functions of IR are manifested in some organizational units in this university. Policy- 
making council and professional ethics council work in the field of university presidency.

The policy council of KUMS was formed for making decisions based on collective wisdom, stakeholders' opinion and experts' ideas to provide macro strategies and tangible measures and programs. The idea behind this council was a management based on policies, monitoring and evaluation, and planning large-scale strategies.

Examining this organizational structure showed that the supervision and accreditation of treatment affairs were actively pursued in the DRMD as one of the functions of IR to improve the quality of patient services and safety. In this unit, standards and evaluation measures were defined, and the scoring of health centers was based on the measurements of different axes of accreditation. In addition, as seen in the structure of the university, in the research and evaluation function, offices such as the Research and Development Office at the DRMD, and research work in education at the ED are active in this regard. Universities of medical sciences and health services revolve around two dimensions, namely education and treatment. In the structure of KUMS, where most of the functions and roles of IR are played at the EDC under the supervision of the ED, the most important activities of the DRT are associated with the role of IR in relation to the Health Technology Development Manager, which is integral to the relationship with industries and commercialization. A comparative study by Toroghi et al. (2017) examined the tasks of IR offices in US universities and compared them with the 18 IR activities proposed by Volkwein. Harvard University met 15 aspects (83\%) of the 18 activities, and the University of South Carolina had the lowest similarity (23\%) to the university's research office compared to the 18 IR activities. In the present study, only eight (47\%) of the 17 activities derived from the results were similar to the functions of the university's research office, eight of which were rather isolated and dispersed over different units and were not targeted (16).

\subsection{Conclusions}

This study examined the status of IR at KUMS and suggests that the goals of IR are not well covered by the various units of this organization. In some cases, the covered areas were partial and isolated. The results also showed that, upon examination and application, the statistics and information presented by the university's various units, such as the Research and EDC, were not quite as comprehensive as the managers had wanted and were not fully reliable for academic decision-making. Similar activities may be performed at the level of information and data production and promotion at KUMS, but the deeper levels of these activities, i.e. changing data to information and the transfor- mation of data and information into knowledge, are not performed. The results can work as a guide for thinking and action for the establishment of an IR office at Iranian medical universities.

\section{Supplementary Material}

Supplementary material(s) is available here [To read supplementary materials, please refer to the journal website and open PDF/HTML].

\section{Acknowledgments}

This paper has been extracted from a PhD thesis in Higher Education Management at School of Graduate Studies, Allameh Tabataba'i University. The project was funded by the National Agency for Strategic Research in Medical Education in Tehran, Iran (grant No. 960297). We would like to express our gratitude to all the officials and individuals who helped complete the study.

\section{Footnotes}

Authors' Contribution: Study concept and design: Mansour Rezaei and Vida Sepahi. interpretation of data: Abbas Abbaspour, Parviz Saketi, and Farid Najafi. Drafting of the manuscript: Mansour Rezaei and Ahmad Khoshay. Critical revision of the manuscript for important intellectual content: Mansour Rezaei, Vida Sepahi, and Abbas Abbaspour.

Conflict of Interests: The authors declare no conflicts of interest.

Funding/Support: The National Agency for Strategic Research in Medical Education funded this research, including personnel and executive costs.

\section{References}

1. Douzi Sorkhabi M. [The quality in higher education]. Tehran: SAMT Publication; 2012. Persian.

2. Damari B, Vosoogh Moghadam A, Rostamigooran N. Stakeholders' network in Iranian health policy-making: A model for participatory policy-making. Med J Islam Repub Iran. 2017;31:106. doi: 10.14196/mjiri.31.106. [PubMed: 29951407]. [PubMed Central: PMC6014780]

3. Volkwein JF. The foundations and evolution of institutional research. New Direction High Educ. 2008;2008(141):5-20. doi:10.1002/he.289.

4. Swing RL, Ross LE. A new vision for institutional research. Change Mag High Learn. 2016;48(2):6-13. doi:10.1080/00091383.2016.1163132.

5. Knight WE. In their own words: Effectiveness in institutional research. North East Association for Institutional Research November 4-7, 2006, Philadelphia, PA; 2006. 85 p.

6. Altbach PG, Salmi J. The road to academic excellence: The making of world-class research universities. World Bank Group. 2011. doi: 10.1596/978-0-8213-8805-1. 
7. Amin Bidokhti AA, Nemati MA, Zare M. [The necessity of establishing a university research unit at Islamic universities of Iran]. Manage Islamic Univ. 2012;1(1):90-113. Persian.

8. Calderon A. Challenges and paradigms for institutional research in a globalised higher education system. Keynote address, Fourth Conference of UK and Ireland Institutional Research. 2011.

9. Delaney AM. Institutional researchers' expanding roles: Policy, planning, program evaluation, assessment, and new research methodologies. New Direction Institut Res. 2009;2009(143):29-41. doi: 10.1002/ir.303.

10. Volkwein JF. The four faces of institutional research. New Direction Institut Res.1999;1999(104):9-19. doi:10.1002/ir.10401.

11. Ministry of Health and Medical Education. [high council of medical ethics]. Ministry of Health and Medical Education; 2017. Persian.

12. Ministry of Health and Medical Education; High Council of Medical Ethics. The second strategic plan of medical ethics in the Islamic Republic of Iran. 2017.

13. Masoud Sinaki S, Seyed Naghavi MA. [Organizational diagnosis by Weisbord's model: Case study of Tehran University of Medical Sciences]. Payavard. 2017;10(6):461-9. Persian.

14. Nemati MA. [Optimizing the exploration of the world's most experiences of institutional research and explaining the place of this units in universities (A case study of Allameh Tabatabaei University)]. QJ Innovation Entrepreneurship. 2016;5(9):1-16. Persian.
15. Marjaei SH. [Study the experiences of university studies at US universities and formulate a model for Iranian universities]. Research Project. Institute of Research and Planning in Higher Education; 2013. Persian.

16. Toroghi J, Arefi M, Yamani Douzi Sorkhabi M, Marjaei SH. [Comparative study of institutional research: Presenting matrix of institutional research]. Motaleat Barnamehrizi Amouzeshi. 2017;6(11):33-53. Persian.

17. Farasatkhah M. [Iranian Universities and quality issue: A survey on Iran's quality assurance system based on the comparative study of 16 countries]. Tehran: Aghah Publication; 2007. Persian.

18. Office of Institutional Research. Harvard University. 2019. Available from: https://oir.harvard.edu/.

19. Office of Institutional Research and Assessment. University Arkansas. 2019. Available from: https://oir.uark.edu/.

20. Office of Academic Affairs, Student Affairs, and International Relations. University of Massachusetts. 2019. Available from: https://www. umassp.edu/aasair/institutional-research.

21. Office of Strategic Planning and Institutional Research. University of Notre Dame. 2019. Available from: https://ospir.nd.edu/institutionalresearch/.

22. Office of Institutional Research. University of Georgia. 2019. Available from: https://oir.uga.edu/.

23. California Association for Institutional Research. 2019. Available from: https://cair.org/. 